\title{
A SUCCESSFUL MANAGEMENT OF EXTENSIVE ALOPECIA AREATA IN CHILDHOOD: A CASE REPORT
}

\author{
Padmavathy $M^{1}$, Krishnakanth $M^{2}$, Adikrishnan $S^{3}$, Murugan $S^{4}$, Mahalakshmi Veeraraghavan ${ }^{5}$
}

1 Junior Resident, Department of Dermatology, Sri Ramachandra Medical College and Research Institute.

${ }^{2}$ Associate Professor, Department of Dermatology, Sri Ramachandra Medical College and Research Institute.

${ }^{3}$ Associate Professor, Department of Dermatology, Sri Ramachandra Medical College and Research Institute.

${ }^{4}$ Professor, Department of Dermatology, Sri Ramachandra Medical College and Research Institute.

5 Professor, Department of Dermatology, Sri Ramachandra Medical College and Research Institute.

\section{ABSTRACT}

Alopecia Areata (AA) is a T-cell mediated autoimmune condition with non-scarring form of hair loss over scalp and/or body. In India and Singapore, one-third of newly diagnosed AA cases have been reported with age less than 20 years. Therapeutic options are limited in children because of lesser tolerability and potential side-effects. Hence, it becomes a challenge to treat extensive alopecia areata in children. We report a 9-year-old girl with extensive alopecia areata who showed no improvement with standard Oral Mini Pulse (OMP) of prednisolone for one year. After starting OMP with prednisolone along with cyclosporine, she showed almost complete regrowth of scalp and body hair in a span of 6 months with no side effects. Hence, we suggest OMP and cyclosporine as a better option for severe progressing alopecia areata in recalcitrant patients.

\section{KEYWORDS}

Alopecia Universalis, Cyclosporine, Oral Mini Pulse.

HOW TO CITE THIS ARTICLE: Padmavathy M, Krishnakanth M, Adikrishnan S, et al. A successful management of extensive alopecia areata in childhood: a case report. J. Evolution Med. Dent. Sci. 2016;5(19):989-990, DOI: 10.14260/jemds/2016/229

\section{INTRODUCTION}

Alopecia areata is a non-scarring, loss of hair over scalp and/or body. It is a T-cell mediated autoimmune condition that affects genetically predisposed individuals. It was first described by Cornelius Celsus and the term AA was coined by Sauvages in $1760 .{ }^{[1]}$ AA has a reported incidence of $0.1-0.2 \%$ with a life-time risk of $1.7 \%$.[2] Although, it can occur at any age, the peak incidence is between 20 and 50 years of age.[3] Both males and females are equally affected, but some studies have reported a male preponderance as well.[1,2] Children accounted for about $20 \%$ of cases with $60 \%$ experiencing their first patch before 20 years of age. ${ }^{[4]}$ Family members are affected in $8.7-20 \%$ of cases.[1,4] Some of the severe forms of AA like extensive $\mathrm{AA}$, alopecia totalis and alopecia universalis are very difficult to treat. Although various therapeutic modalities are available for treating AA, none has been found to be satisfactory. We report this case of 9-year-old who experienced a complete hair growth in spite of poor prognostic factors.

\section{CASE REPORT}

A 9-year-old girl presented with asymptomatic patch of hair loss of 4 years' duration. It progressively increased to involve eyebrows and body hair. There were no features of inflammation, scarring or atrophy. The patient was atopic with no relevant family history. On examination, we noticed seven large patches of hair loss with oophiasis, thinning of eyebrows and complete loss of body hair. Dystrophic nail changes were present on all fingers and toes. Rest of the physical examination were unremarkable. \{Figure 1a, 2a\}

Financial or Other, Competing Interest: None.

Submission 23-01-2016, Peer Review 17-02-2016,

Acceptance 23-02-2016, Published 07-03-2016.

Corresponding Author:

Padmavathy $M$

95/11 Vaishnav Aprts, Gill Nagar,

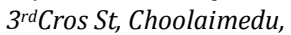

Chennai-94.

E-mail: drpadma_02@yahoo.com

DOI: $10.14260 /$ jemds/2016/229
On further enquiry patient revealed that she took Tablet Prednisolone $20 \mathrm{mg}$ for 2 years, after which she discontinued treatment at which time the alopecia areata progressed. After investigations, she was started on $50 \mathrm{mg}$ of cyclosporine daily. Further to arrest the disease activity, $20 \mathrm{mg}$ prednisolone weekend pulse therapy was given with low dose. The child was followed up every 2 weeks with clinical examination and serial photographs. Blood pressure and blood investigations were monitored frequently. Regrowth of hair was noticed over body and eyebrows within 1-2 months and scalp hair attained their full growth after 3-6 months of treatment. The clinical response was good with no side effects. \{Figure 1b, 2b\}.

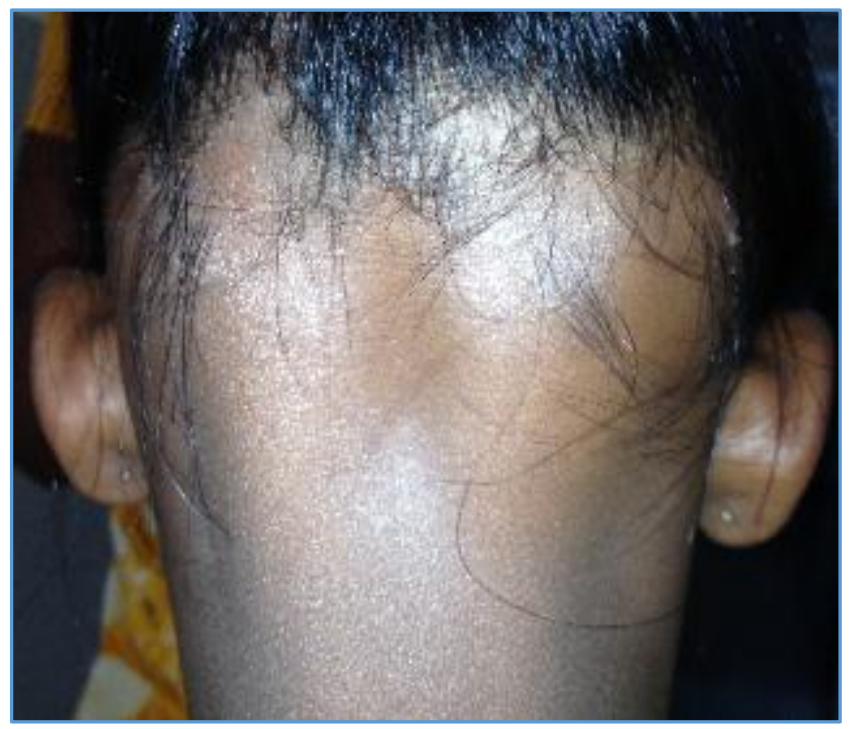

Fig. 1(a) 


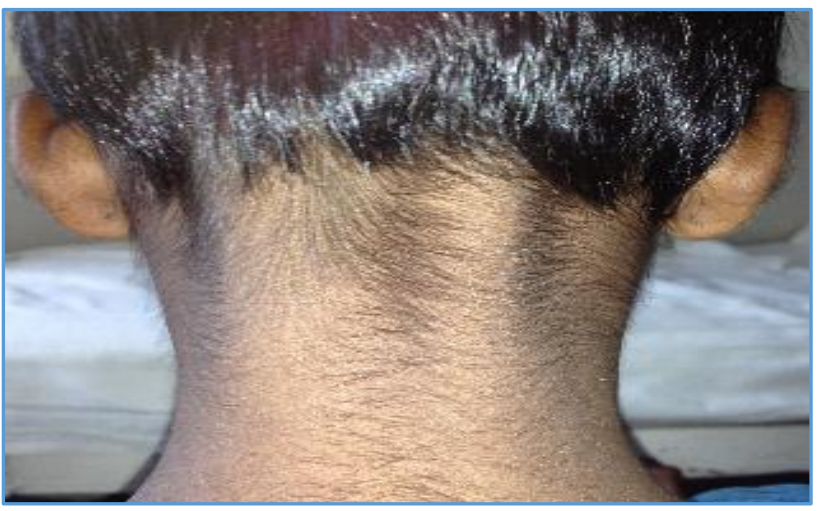

Fig. 1(b)

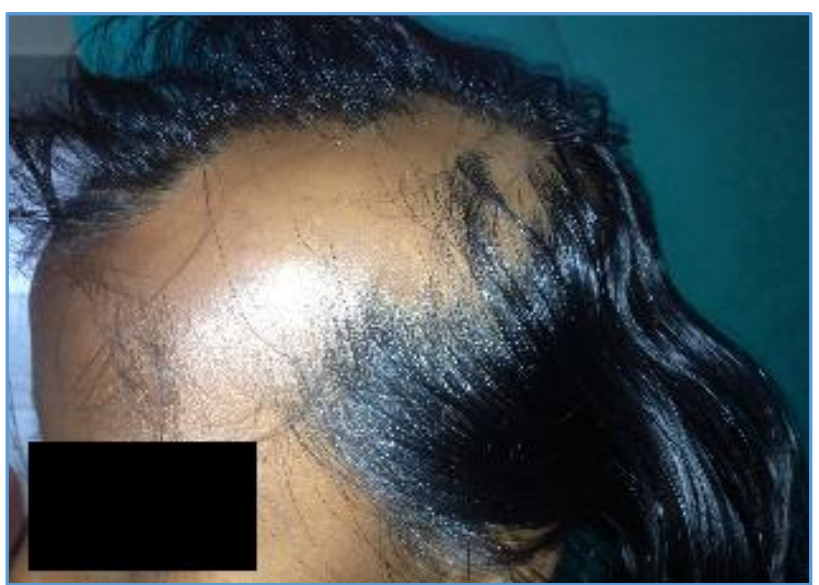

Fig. 2(a)

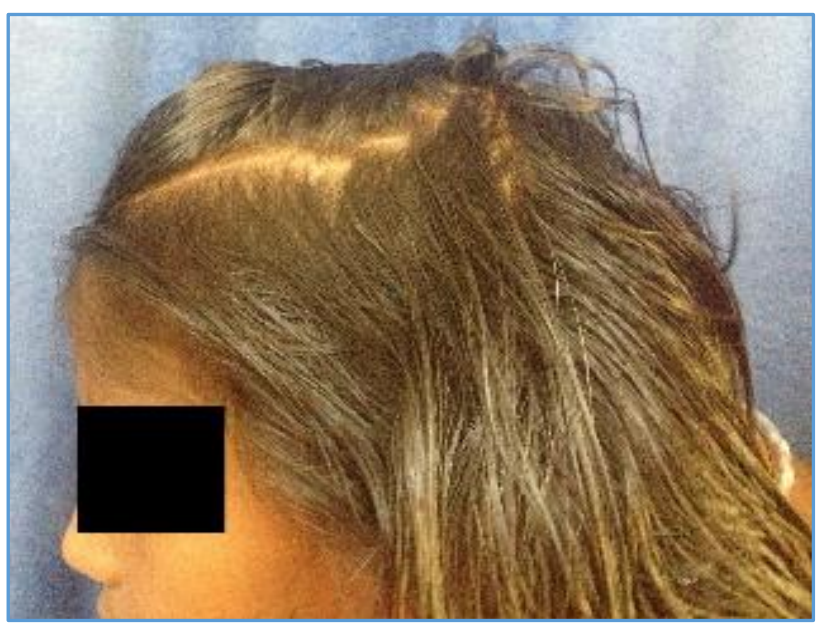

Fig. 2(b)

\section{DISCUSSION}

Alopecia areata may present as well demarcated single or multiple patches of hair loss or extensive hair loss in the form of total loss of scalp hair (Alopecia totalis) or loss of entire scalp and body hair (Alopecia universalis). Since AA can cause cosmetic and psychological disability, especially in children and women, it is essential to diagnose and treat appropriately. Sharma et al. reported male preponderance among North Indians (M:F=2:1).[1] Although literature evidence showed a higher incidence of severe alopecia in boys or men with onset at an earlier age, our case differed in this with severe disease in female child with the onset at 5 yrs. of age. Atopy, positive family history, nail changes like twenty nail dystrophy have been associated with paediatric
AA. Nail changes are more frequent in children (50\%) than in adults (29\%).[5] Presence of severe alopecia, oophiasis, nail changes or atopy, onset before 20 years of age, family history of alopecia, duration more than 1 year were found to be poor prognostic factors.

AA can be classified into two groups. In the first group of patients, the disease usually starts with one or more patches of hair loss and its size continues to increase over first 2-4 weeks and becomes static thereafter. The hair tends to regrow without any treatment. Thus, observation for spontaneous hair regrowth is a reasonable option for young children with limited disease.

The second group of patients will have few patches of hair loss initially, but may progresses to alopecia totalis or universalis. Autoimmune mechanisms play a significant role. Treatment is indicated in such patients if there is no spontaneous regrowth even after 3-6 months of onset.

A large variety of therapeutic modalities have been suggested for the treatment of AA, which include topical steroids, contact sensitizers such as dinitrochlorobenzene, squaric acid dibutylester and diphenylcyclopropenone or a tacrolimus, anthralin, nitrogen mustard or minoxidil. Systemic therapy includes corticosteroids, sulfasalazine, methotrexate and cyclosporine. Photochemotherapy with PUVA, excimer laser and excimer light can also be tried. $[3,6,7,8]$ All have their own limitations and advantages.

The localized forms respond very well to topical or intralesional corticosteroids. The severe forms are difficult to treat. In our patient even with poor prognostic factors, she showed an excellent response with cyclosporine and oral mini pulse without any side effects.

\section{CONCLUSION}

We would conclude that wait and watch will be the best option for mild forms of alopecia areata, whereas a more aggressive approach is indicated in severe forms with cyclosporine and prednisolone pulse therapy yielding good results.

\section{REFERENCES}

1. Sharma VK, Dawn G, Kumar B. Profile of alopecia areata in northern India. Int J Dermatol 1996;35:22-7.

2. Tan E, Tay YK, Goh CL, et al. The pattern of alopecia areata in Singapore-a study of 219 Asians. Int J Dermatol 2002;41:748-53.

3. Imran Majid, Abid Keen. Management of alopecia areata: update. BJMP 2012;5(3):a530.

4. Wasserman D, Guzman-Sanchez DA, Scott K, et al. Alopecia areata. Int J Dermatol 2007;46:121-31.

5. Tosti A, Morelli R, BardazziPeluso AM. Prevalence of nail abnormalities in children with alopecia areata. PadiatrDermatol 1994;11:112-5.

6. Shapiro J. Alopecia areata. Update on therapy. In: Maddin S, McLean Dl, eds. Dermatol clinics. Philadelphia: Saunders, 1993;11:35-46.

7. Ashworth J, Tuyp E, Mackie RM. Allergic and irritant contact dermatitis compared in the treatment of alopecia totalis and universalis. A comparison of the value of topical diphencyprone and tretinoin gel. $\mathrm{Br} \mathrm{J}$ Dermatol 1989;120:397-401.

8. Olsen A, Carson SC, Turney EA. Systemic steroids with or without $2 \%$ topical minoxidil in the treatment of alopecia areata. Arch Dermatol 1992;128:1467-73. 